\title{
Estrategias de desplazamientos discursivos en cuerpos de oposición parlamentaria en Argentina
}

\section{Discursive displacements strategies in parliamentary opposition bodies in Argentina}

doi: https://doi.org/10.32870/eees.v26i75.7046

\author{
Víctor Humberto Guzmán* \\ Candelaria Sgró Ruata*
}

\begin{abstract}
Resumen
Este artículo analiza la oposición parlamentaria en Argentina entre 2009 y 2010 , en casos en los que se debatieron reformas legales por la ampliación de derechos vinculados con la ciudadanía comunicativa y sexual. A partir del análisis de las intervenciones en las sesiones de votación del Congreso, se proponen dos categorías para describir estrategias de desplazamiento de la oposición parlamentaria: desplazamientos por fallas procedimentales y desplazamientos por rencillas políticas. Se concluye que ambas categorías agrupan operaciones discursivas que cuestionan la institucionalidad democrática con base en factores externos, desplazan los objetos de discusión legislativa y persiguen la anulación del debate parlamentario.
\end{abstract}

Palabras clave: derechos sexuales $y$ reproductivos, derechos de la comunicación, oposición parlamentaria, matrimonio igualitario, Argentina.

\begin{abstract}
This article analyzes the Argentinan parliamentary opposition in legal reform debates between 2009 and 2010, that searched to extend rights concerning to communicative and sexual citizenship in that country. From analysis of interventions in the Congress' voting sessions, the paper proposes two categories to describe strategies of displacement of the parliamentary opposition: displacements by procedures flaws and displacements by political feuds. Both categories group discursive operations that question the democratic institutions based on external factors, displace the object of legislative debate and seek the annulment of parliamentary debate.
\end{abstract}

Keywords: Sexual and reproductive rights, communication rights, parliamentary opposition, same-sex marriage, Argentina.

-Profesor-Investigador del Centro de Estudios Avanzados de la Facultad de Ciencias Sociales y de la Facultad de Derecho de la Universidad Nacional de Córdoba (UNC), y becario posdoctoral del Centro de Investigaciones y Estudios sobre Cultura y Sociedad y del Consejo Nacional de Investigaciones Científicas y Técnicas (Conicet), Argentina. ORCID: http://orcid. org/0000-0003-0302-9776_vhg1978@gmail.com

- Profesora-Investigadora de la Universidad Nacional de Córdoba (UNC), y del Consejo Nacional de Investigaciones Científicas y Técnicas (Conicet), Argentina. ORCID: http://orcid. org/0000-0002-4842-333I__candelariasgro@yahoo.com _

Fecha de recepción: 04 de abril de 2018. Fecha de aceptación:04 de diciembre de 2018 . 


\section{Introducción}

$\mathrm{Al}$ inicio del siglo xxI, los escenarios políticos de distintos países de América Latina se encuentran marcados por los denominados Gobiernos progresistas (Retamozo, 2011; Stoessel, 2014). En este contexto, en Argentina, ciertas demandas por el reconocimiento y ampliación de derechos cobraron fuerza pública e incluso lograron ingresar a las agendas parlamentarias en los primeros años del siglo.

Este trabajo se propone abordar en términos generales el campo de las demandas expansivas de derechos en la Argentina reciente. El objetivo es analizar las estrategias discursivas de la oposición parlamentaria en dos debates que politizaron la ampliación de derechos, en este caso, comunicativos y sexuales. Se prioriza al Poder Legislativo por ser una de las instituciones formales fundamentales de la democracia representativa.

Para ello, primero se exponen algunas pistas de contextualización para que funcionen como marco de reflexión para la exploración y el análisis de los datos empíricos. En segundo lugar, se realiza un paneo por los casos elegidos para este trabajo (debates), en el que se mencionan las características generales de los proyectos de ley seleccionados. En tercer lugar, se exponen los procedimientos metodológicos implementados con el material empírico. Finalmente, se desarrollan las dos categorías que agrupan las operaciones discursivas analizadas en términos de desplazamientos. Estos desplazamientos se evidencian como centrales, como puntos o anclajes comunes a partir de los cuales se caracterizan algunas estrategias de oposición parlamentaria.

Como se advertirá luego, aunque el trabajo parte de discusiones sobre democracias representativas contemporáneas, no pretende profundizar estas discusiones, sino tomar algunos casos del contexto argentino reciente para abrir líneas 
de problematización sobre las estrategias discursivas de la oposición parlamentaria en ese mismo contexto. De manera secundaria, el objetivo es también plantear algunos interrogantes que, desprendidos del análisis empírico, actúan como disparadores para considerar ciertas características que se piensan como lo paradójico de estas estrategias.

\section{Contexto general}

En distintos países de América Latina, tras el periodo de los Gobiernos neoliberales de los años noventa, se presentó el llamado giro a la izquierda, que con mayor o menor intensidad involucró a los Gobiernos de la década subsiguiente. Este fenómeno habilitó la puesta en escena de distintas discusiones que generaron tensión en las continuidades y rupturas con el modelo neoliberal (Retamozo, 2011).

En Argentina, luego de tres décadas de democracia postdictatorial, una serie de debates de largo aliento fue tomando espacio en el ámbito público, impulsada principalmente por organizaciones y movimientos sociales. Según algunos estudios (Retamozo, 2011; Natalucci, 2011), en el periodo de los Gobiernos kirchneristas (2003-2015), ${ }^{1}$ se implementó una política de articulación con los movimientos y organizaciones sociales, cuyo devenir repercutió intensamente en la reconstrucción de las relaciones entre estos y el Estado.

En este contexto sociohistórico, ciertas demandas por ampliación y reconocimiento de derechos lograron fuerza pública e incluso ingresaron en las agendas parlamentarias. Entre ellas, interesan a este trabajo dos demandas puntuales relacionadas con la ciudadanía sexual y la ciudadanía comunicativa que, hacia fines de la década de los dos mil, generaron una significativa movilización política y social en el país y devinieron en la aprobación de dos leyes: la Ley 
de Servicios de Comunicación Audiovisual (2009) (LSCA), o Ley 26522, y la Ley de modificación del código civil para el reconocimiento del matrimonio de parejas sin distinción de sexos (2010), conocida como de matrimonio igualitario (MI), o Ley 26618. Muchos estudios identifican estas dos normativas, entre otras, como centrales en lo relacionado con procesos de democratización, universalización de derechos e inclusión durante este periodo (Biglieri, 2013; Berdondini, 2016; La Serna, 2015; Retamozo, 2011; Bonetto y Martínez, 2012; Rodríguez Villafañe, 2009).

Vale decir que el periodo de los Gobiernos kirchneristas interesa aquí en tanto contexto de aprobación de las leyes señaladas. No se pretende reconstruir o recuperar las distintas líneas que analizan el kirchnerismo, tanto hacia el interior del campo político argentino como a nivel regional o internacional. Tampoco se pretende dar cuenta de las dimensiones que tensionan las continuidades o rupturas de las políticas implementadas durante el periodo; de hecho, estas cuestiones, entre otras, han sido motivo de un intenso debate académico, y por ello, de distintas formas de analizar el kirchnerismo (ver, por ejemplo: Bonetto y Martínez, 2012; Pérez y Natalucci, 2012).

Por otro lado, a partir del estudio de Stoessel (2014), se puede observar que la emergencia del giro a la izquierda de principios del siglo xxI en la región suscitó importantes debates académicos y políticos, principalmente en el marco de la producción del campo de las ciencias sociales. Estas producciones, cuyos enfoques y posicionamientos son variados y continúan generando controversias, se centran en la necesidad de analizar las características que asumieron las experiencias singulares en los procesos políticos contemporáneos en América Latina.

Del entramado referido, la cuestión que se recupera en este trabajo es la producción de debates sociopolíticos que en este contexto han logrado llevar demandas históricas de 
movimientos sociales o sectores organizados de la sociedad civil al Congreso Nacional argentino con el objetivo de transformar los marcos normativos vigentes. En otras palabras, durante este periodo, ingresaron al debate parlamentario demandas por la ampliación y reconocimiento de derechos que al mismo tiempo generaron una fuerte resistencia. Este fue el denominador común de los debates por la sanción de las leyes LSCA y MI.

Como se trata de procesos de expansión y reconocimiento de derechos de largo aliento en Argentina, las aristas desde las que pueden abordarse las leyes señaladas son variadas e implican distintos niveles de complejidad. Esto se especifica en especial por el marco general, como se mencionó antes, en el que se presentan como procesos, que se combina con los cambios de los Gobiernos de la región (Stoessel, 2014).

En los apartados siguientes, se sintetiza el recorrido de ambos proyectos de ley en el marco formal de las Cámaras Legislativas, con algunos señalamientos sociopolíticos. La finalidad de este resumen es introducir algunos componentes, que se entienden en este panorama como principales, sobre el contexto social y formal legislativo en que ocurrió el debate parlamentario que culminó con la sanción de las leyes.

\section{El proyecto de Ley 26522 de Servicios de Comunicación Audiovisual}

A mediados del 2008, la Cámara de Diputados de la Nación declaró de interés los veintiún puntos básicos por el derecho a la comunicación, con el objetivo de encarar la construcción de una nueva ley de radiodifusión (Honorable Cámara de Diputados de la Nación, 2008). El documento, conocido simplemente como Veintiún puntos, había sido elaborado en 2004 por un colectivo de diversas organizaciones gremiales y universitarias y radios comunitarias, entre otras, conocido como Coalición por una Radiodifusión 
Democrática. Este colectivo articuló recursos materiales y simbólicos con el objetivo de "fijar pautas esenciales que deben contemplarse en una nueva norma en la materia que se tiene que dictar para la democracia" (Rodríguez Villafañe, 2009, p. 311).

La normativa vigente hasta la sanción de la LSCA en Argentina era la Ley de Radiodifusión (Ley 22285), sancionada en 1980 durante el periodo marcado por la última dictadura militar (1976-1983). Entonces, habían transcurrido más de dos décadas desde el cambio democrático en Argentina, y la coalición se organizó y movilizó para demandar nuevos marcos normativos orientados por el reconocimiento de derechos a la comunicación, que suponen y desbordan los de la infomación y la expresión.

Sin dudas, la conformación de la coalición se posicionó como un antecedente relevante, y el trabajo realizado por el colectivo sostuvo en gran parte la presentación que realizó en 2009 el Poder Ejecutivo Nacional (PEN). El 18 de marzo de ese año, el PEN presentó públicamente la Propuesta de proyecto de Ley de Servicios de Comunicación Audiovisual, con el fin de discutir un nuevo marco normativo que reemplazara la ley vigente entonces, como ya se dijo, sancionada en los ochenta.

A partir de esta presentación, se inició un periodo de discusiones en foros participativos de consulta pública (FPCP) organizados en diferentes provincias argentinas para discutir y realizar aportes a la propuesta de reforma legal antes de que fuera enviada al Congreso de la Nación (Rodríguez Villafañe, 2009). Durante los meses de abril, mayo y junio de 2009, se realizaron veintitrés FPCP, y en ellos participaron diversos actores y organizaciones sociales que expresaron su posición frente a la reforma legal (Guzmán, 2012). ${ }^{2}$

2. En un trabajo anterior, se presentó un mapa de los actores y organizaciones participantes en los FPCP implementados por los impulsores formales de la propuesta, el PEN y el Comité Federal de Radiodifusión (COMFER) (Guzmán, 2012).

\section{6}


En el mes de agosto, finalizado este periodo de discusiones, el PEN ingresó a la Cámara de Diputados de la Nación el proyecto de la LSCA, lo que inició su proceso en el Poder Legislativo. En el mes de septiembre, las comisiones legislativas encargadas de discutir el proyecto, ${ }^{3}$ en reunión conjunta, decidieron convocar a audiencias públicas. Estas se iniciaron el 8 de septiembre y continuaron hasta completar cuatro jornadas en las que participaron distintos sectores sociales que manifestaron su opinión respecto al proyecto de ley. Así, el texto original del proyecto presentado por el PEN fue modificado en parte considerando los aportes recogidos en el marco de las audiencias y lo promovido por legisladores que discrepaban de la propuesta.

Trascurrido un mes de la presentación del proyecto hecha por el PEN, el 16 de septiembre, el proyecto de la LSCA se debatió en el recinto de los diputados. Esta sesión parlamentaria estuvo marcada por la decisión de no participar en ella que tomaron las fuerzas políticas contrarias al proyecto en discusión. De este modo, de los doscientos cincuenta y siete diputados que conforman la Cámara, se registraron como ausentes ciento cuatro, pertenecientes a distintas fuerzas políticas ${ }^{4}$ (entre ellas, la Unión Cívica Radical y la Coalición Cívica, fuerzas partidarias que se conformaban como las primeras minorías de la Cámara).

3. Comisiones de Comunicación e Informática, Presupuesto y Hacienda y Libertad de Expresión de la Cámara de Diputados.

4. Bloques políticos que se registraron como ausentes: Unión Cívica Radical, Santa Fe Federal, Consenso Federal, Frente Justicia Unión y Libertad, Coalición Cívica ARI-GEN-UPT, Unión Celeste y Blanco, Convergencia Federal, Partido Liberal de Corrientes, Partido Nuevo Contra la Corrupción, Frente de Todos, Unión Peronista, Nacional Sindical, Propuesta Republicana, Frente para la Victoria-Partido Justicialista (PJ) (Graciela Camaño y Miguel Ángel Iturrieta, en disidencia con el bloque), Frente Cívico y Social de Catamarca, Peronismo Federal, Demócrata de Mendoza, Renovador de Salta (María Inés Diez), Buenos Aires por el Cambio, Frente por los Derechos Ciudadanos, Valores para mi País, Peronista Salteño, Frente Producción y Trabajo, Concertación Entrerriana, Memoria y Democracia, Bloque por la Verdad, Frente de Todos, Partido Unidad Federalista, Justicialismo Republicano y Peronista Federal. 
En su lugar, los legisladores presentaron mociones de orden con el objetivo de dejar asentada su posición basada en la impugnación de la legalidad de la sesión. Los fundamentos de esta proposición se centraron en los estatutos reglamentarios de la Cámara Legislativa, con especial hincapié en el artículo 26 del reglamento relativo al tiempo necesario para declarar la nulidad de la sesión (Honorable Cámara de Diputados de la Nación, 2014, p. 26). De todas maneras, dado que se logró el quorum para iniciar la sesión, el debate parlamentario se llevó adelante y el proyecto obtuvo media sanción (Tabla 1), dando paso a su tratamiento en la Cámara de Senadores. ${ }^{5}$ Vale mencionar que la sanción de leyes en Argentina requiere del tratamiento en ambas Cámaras (diputados y senadores), lo que implica también que sean discutidas y aprobadas en ambas instancias.

Tabla 1. Votación general de la LSCA en la Cámara de Diputados de la Nación Argentina (sesión del 16 de septiembre de 2009) ${ }^{6}$

$\begin{array}{ll}\text { Voto } & \text { Total } \\ \text { Afirmativo } & 147 \\ \text { Negativo } & 4 \\ \text { Abstención } & 1 \\ \text { Total } & 152\end{array}$

Fuente: elaboración propia.

En la Cámara de Senadores, se realizó una sesión especial los días 9 y 10 de octubre de 2009, en la que se debatió el proyecto y este obtuvo su sanción definitiva (Tabla 2) y su posterior promulgación, ya como Ley 26522.

5. El proyecto ingresó el 22 de septiembre de 2009 a las comisiones de Sistemas, Medios de Comunicación y Libertad de Expresión, y Presupuesto y Hacienda, y el 23 de septiembre del mismo año a las comisiones de Asuntos Constitucionales e Industria y Comercio.

6. Las Tablas I y siguientes muestran la distribución de la votación final en las sesiones legislativas, por lo que el total informado corresponde a los votos emitidos y no al total de los miembros que integran las Cámaras. 
Tabla 2. Votación general de la LSCA en Cámara de Senadores (sesión del 9 y 10 de octubre de 2009)

\begin{tabular}{ll} 
Voto & Total \\
Afirmativo & 44 \\
Negativo & 24 \\
Abstención & 0 \\
Total & 68 \\
\hline
\end{tabular}

Fuente: elaboración propia.

3. El proyecto de la Ley 26618 de modificación del matrimonio civil

Como se mencionó antes, ni la ley de Mi ni la LSCA se reducen o limitan al momento en que los proyectos ingresaron a las Cámaras Legislativas y consiguieron finalmente su sanción: ambos procesos de aprobación de las leyes involucran y combinan dimensiones complejas con periodicidades sociopolíticas diversas y particulares, tal y como lo han puesto de relieve los estudios que se enfocan en estas dimensiones.

En este sentido, numerosos trabajos han abordado, desde diferentes enfoques, los procesos que culminaron -y se abrieron- con la sanción de la ley de MI en Argentina (Clerico y Aldao, 2010; Solari y Von Opiela, 2011). Aquí vale recuperar algunas de las características que han sido profundizadas por estos estudios.

Una de las principales es la centralidad que tuvieron los movimientos feministas y de la diversidad sexual en la articulación de demandas que avanzaran hacia el reconocimiento de derechos sexuales y reproductivos en Argentina (Vaggione, 2011).

Otra característica importante, relacionada con el activismo de los movimientos sociales en las últimas décadas, 
es el giro judicial de la política (Martín, 2011), esto es, la incidencia legal como herramienta utilizada por el activismo para inscribir demandas de reconocimiento de sus derechos (Delamata, 2013 y 2014). En el caso de la ley de MI por ejemplo, antes de su sanción ya se habían logrado fallos judiciales que reconocían el derecho (Martín, 2011).

En este marco, durante el 2009, en la Cámara de Diputados de la Nación se presentaron proyectos de reforma legal para el reconocimiento de la institución matrimonial a parejas sin distinción de sexos, en línea con otra serie de proyectos legislativos que se habían presentado en años anteriores pero que habían ido perdiendo estado parlamentario (Bimbi, 2010), es decir, no habían llegado a ser discutidos en sesión parlamentaria, lo mismo que había sucedido con otras propuestas realizadas durante 2009 y discutidas sin éxito en comisiones legislativas de Diputados. ${ }^{7}$

Con el inicio del periodo de sesiones del 2010 también reiniciaron las reuniones de las comisiones legislativas, y el 15 de abril de dicho año se firmó un dictamen -de mayoríaque aconsejaba la aprobación del proyecto para la ley de MI. Con la obtención del dictamen, el 4 de mayo, el proyecto se debatió en el recinto de la Cámara de Diputados y obtuvo media sanción (Tabla 3).

Tabla 3. Votación general del proyecto de la ley de mi en la Cámara de Diputados de la Nación Argentina (sesión del 4 de mayo de 2010)

\begin{tabular}{ll} 
Voto & Total \\
Afirmativo & 126 \\
Negativo & 110 \\
Abstención & 4 \\
Total & 240 \\
\hline
\end{tabular}

Fuente: elaboración propia. 
Posteriormente, el proyecto ingresó a la Cámara de Senadores para ser discutido en la Comisión de Legislación General del Senado (CLGS). La CLGS decidió trasladar sus reuniones a diferentes puntos del territorio nacional, con el objetivo de fortalecer el federalismo. Aunque estas reuniones se conocieron como audiencias públicas, en la primera de ellas, realizada por la CLGs en la Legislatura Provincial del Chaco, el 10 de junio de 2010, se advirtió que el evento no era una audiencia pública formal, sino traslados de las reuniones de la comisión legislativa: "[...] esta es una reunión de comisión; se la [sic] denomina audiencia, porque -en realidad- lo es, pero la audiencia pública tiene otro procedimiento administrativo" (Honorable Senado de la Nación, 2010, p. 7). ${ }^{8}$

De esta manera, durante los meses de junio y julio de 2010, se realizaron nueve de estas audiencias en distintas provincias argentinas (Córdoba, Catamarca, Jujuy, Salta, Tucumán, San Juan, Chaco, Corrientes y Mendoza), además de las planificadas en Buenos Aires (provincia y Capital Federal). En ellas, participaron actores y organizaciones sociales que expresaron su posición frente al proyecto. En algunas de estas reuniones, resulta interesante mencionar, estuvieron presentes legisladores representantes de las provincias.

Luego de este conjunto de reuniones, el 6 de julio de 2010, la CLGS acordó un dictamen -de mayoría- que aconsejaba el rechazo del proyecto que venía con media sanción de la Cámara de Diputados. También, se acordaron otros dictámenes - de minoría- entre los que se encontraba el que aconsejaba aprobar el proyecto con media sanción de Diputados, así como proyectos alternativos que aconsejaban la aprobación de una ley que regulara la unión civil.

8. Más allá de la aclaración formal, en el contexto del debate (reuniones de la comisión, sesiones de votación, medios de comunicación y otros diversos espacios de lo público), se utilizó reiteradamente la denominación audiencias públicas. 
Aunque esta situación parecía modificar el eje de lo que se discutiría finalmente en el recinto de senadores, un día antes de la sesión en el Senado, se presentó y aceptó una impugnación al proyecto que proponía la unión civil. Con esta decisión, el 14 de julio se realizó en el recinto el debate sobre el proyecto de ley de Mi, que resultó aprobado tras una extensa sesión (Tabla 4) y convertido en la Ley 26618, publicada en el Boletín oficial núm. 31949 del 22 de julio de 2010.

Tabla 4.Votación general del proyecto de ley de MI en Cámara de Senadores (sesión del 14 de julio de 2010)

$\begin{array}{ll}\text { Voto } & \text { Total } \\ \text { Afirmativo } & 33 \\ \text { Negativo } & 27 \\ \text { Abstención } & 3 \\ \text { Total } & 63\end{array}$

Fuente: elaboración propia.

Por último, en los itinerarios formales de los proyectos de ley trazados hasta aquí, es relevante mencionar lo que respecta a la composición de las Cámaras Legislativas. Entre la sanción de la LSCA (2009) y la sanción del MI (2010), en concreto en el mes de junio de 2009, se realizaron en Argentina elecciones para renovar bancadas en ambas Cámaras. El oficialismo perdió la mayoría que poseía en el Poder Legislativo. Los legisladores electos asumirían su mandato en el mes de diciembre de 2009, por lo que entre la discusión y votación de la LSCA (sancionada en octubre de 2009) y la ley de Mi (sancionada en julio de 2010) se produjo un recambio en la composición del Congreso Nacional.

Por otro lado, aunque con sinergias diferentes, e incluso considerando la renovación en la composición de las Cámaras Legislativas, ambas leyes ingresaron a la agenda parlamentaria acompañadas de intenso activismo y parti-

\section{2}


cipación. En este contexto, a pesar de las distancias que podrían advertirse entre los temas en debate (las trayectorias de los proyectos de cada ley, por ejemplo), pueden identificarse puntos comunes entre ambas leyes en tanto sentidos puestos en circulación pública por los cuerpos de oposición parlamentaria que abren lecturas sobre la resistencia a la transformación del statu quo operante.

\section{La oposición parlamentaria como objeto}

Poner el foco en la oposición, en particular en los países de América Latina, con larga historia de democracias interrumpidas, se vuelve un asunto relevante para el presente análisis, principalmente si se considera el papel que las fuerzas políticas (o partidos) juegan en sistemas democráticos consolidados. Distintos trabajos han mostrado la complejidad del término oposición (Barrientos del Monte, 2015), así como el papel que desempeña la oposición política en los regímenes democráticos (Rodríguez, 2015).

Además del estudio clásico de Dahl (1989), en el que plantea a la oposición como uno de los elementos centrales de una poliarquía, numerosos estudios advierten el rol de la oposición como una dimensión sustancial para la calidad de la democracia en los sistemas democráticos contemporáneos (Morlino, 2012; Altman y Pérez-Liñán, 2001; Diamond y Morlino, 2004).

En este trabajo, se asume que parte del problematizar una democracia de calidad implica comprender la acción de la oposición como actor del juego político democrático desde un enfoque que desplace momentáneamente a las fuerzas o partidos políticos como actores en sí para ubicarlos en la discursividad, esto es, las significaciones que atraviesan, sustentan y alientan lo dicho y hecho por los actores políticos en el espacio de lo público. Desde esta perspectiva, el desafío es, entonces, analizar la oposición como campo discursivo, 
con foco en el Poder Legislativo (el debate parlamentario), para observar allí su materialidad.

Se entiende aquí que enfocarse en el Poder Legislativo es importante no sólo porque en el marco de esta forma institucional se decide el futuro de una norma (público fuerte, en los términos de Fraser-1997-), sino porque dicho poder ofrece un momento de observación clave: el debate parlamentario (instancia singular de toma de la palabra en la discusión de una votación) habilita el reconocimiento de los puntos o anclajes en los que la oposición se materializa (se hace argumento, se construye, se justifica). Estos puntos o anclajes (vinculados ahora a las significaciones articuladas en la escena pública) permiten dar cuenta de aquello que emerge como común (más allá de las filiaciones partidarias) en momentos en los que la ampliación de derechos se presenta como campo en disputa. En el marco de estas consideraciones, se define entonces a la oposición parlamentaria como un campo discursivo cuya materialización se observa en el debate parlamentario (puntualmente, en las sesiones de votación de las leyes).

El discurso parlamentario puede pensarse como un género a partir de la esfera específica de comunicación en la que se da (Bajtín, 1997), o bien como subgénero de lo que algunos autores definen como discurso político (Ionescu-Ruxăndoiu, 2012a) o como tipo de discurso político (Verón, 2004). En este campo, diversos estudios han analizado las peculiaridades de los debates parlamentarios. ${ }^{9}$

Por ejemplo, Carbó (1993), que estudia el caso mexicano, señala al parlamentario como un complejo fenómeno discursivo compuesto por formas discursivas que suponen diversos tipos de actividad verbal -oral, escrita, cara a 
cara, etc.- que al momento del debate asumen un carácter básicamente polémico.

Para el caso del Parlamento argentino, Bitonte y Dumm (2007) definen la particular dinámica interaccional del debate como triangular (no bivocal), esto es, los legisladores no interactúan cara a cara, sino que lo hacen mediados por el presidente de la Cámara, que es quien designa los turnos de la toma de la palabra y a la vez a quien se dirigen las intervenciones. Así, se puede reconocer que en el caso de un debate parlamentario existen determinadas normas y reglas del juego que van marcando las posibilidades de enunciación (turnos de habla, lista de oradores, instancias de decisión, fuerzas partidarias, afiliaciones políticas, etc.).

Ahora bien, el enfoque y los supuestos conceptuales de un estudio definen en gran parte las maneras en las que una instancia empírica es abordada. En la exploración realizada para este trabajo, se encontró una diversidad de estudios que abordan el debate parlamentario como un género discursivo, y por lo tanto, sujeto a la identificación de determinadas características. Esto suscitó una serie de preguntas respecto a cómo abordar el debate considerando ciertos presupuestos conceptuales-epistemológicos y una propia mirada que considera a los discursos como social, política y sociológicamente relevantes en tanto se inscriben en un campo en disputa.

Las herramientas analíticas derivadas de las perspectivas que utilizan la noción de géneros discursivos son sumamente útiles al momento de trabajar con los materiales. Sin embargo, interesa fundamentar por qué para este trabajo no se aplica dicha noción. Aun cuando esta noción suponga el solapamiento de numerosos tipos, justamente por el enfoque asumido en este trabajo, lo que guía la reflexión es el modo en que se delinean zonas de significación cuyos límites no son rígidos. Puntualmente, en este marco, interesan las formas en las que el movimiento de resistencia (conser- 
vadurismo) a la ampliación social de derechos da forma a una configuración de universos de sentido conectada con el campo de disputa en determinadas sociedades pensadas como institución (Castoriadis, 2007).

Así, en este trabajo se entiende al debate parlamentario como una modalización de lo público; como espacio donde la sociedad se enuncia a sí misma (Caletti, 2001, 2006 y 2007); como espacio público fuerte (Fraser, 1997); y como instancia formal institucionalizada y legítima de nuestras sociedades democráticas, donde se decide finalmente el futuro del ordenamiento jurídico, es decir, de las normas y leyes que -al menos por un tiempo-guiarán las prácticas (el poder hacer) de una sociedad situada, sociedad que a su vez se despliega en la dinámica de un juego de tensiones entre significaciones sociales imaginarias (Castoriadis, 2007) y en esas tensiones configura (va configurando) las diferentes formas del hacer y el decir social.

Desde este enfoque, el presente estudio no se orienta sólo a problematizar algunas dimensiones de la oposición en general o de la oposición parlamentaria en particular: se parte del supuesto de la centralidad de la oposición en el debate parlamentario para la consolidación de la institucionalidad democrática, por lo que la oposición -en general, y la parlamentaria en particular-es entendida aquí como un componente "característico y distintivo de las democracias" (Zucchini, 1998, p. 848), y este supuesto es el que opera como una de las condiciones reflexivas y marco de análisis.

\section{Lineamientos teórico-metodológicos}

En este trabajo, se considera que "tanto las palabras como las acciones pueden ser entendidas como signos y, por lo tanto, como discursos" (Cabrera, 2006, p. 75). Así, se postula lo discursivo como constelación de significados cuyo soporte puede ser lingüístico o extralingüístico y que 
funcionan, a su vez, como condiciones de posibilidad de otros discursos (Verón, 1998). Más específicamente, “cualquiera que fuere el soporte material, lo que llamamos un discurso o un conjunto discursivo no es otra cosa que una configuración espacio-temporal de sentido" (Verón, 1998, p. 127).

Los fenómenos de sentido aparecen, entonces, bajo la forma de conglomerados de materia significante que remiten a una red interdiscursiva más amplia que se postula como sistema productivo. Este modelo permite el acceso a la red semiótica partiendo del análisis de fragmentos de la semiosis, ya que bajo la hipótesis de que todo sistema productivo deja huellas en sus productos se puede acceder al primero a través del segundo.

Sobre estos lineamientos, la apuesta de este trabajo es realizar una lectura-análisis transversal, a partir de un acercamiento hermenéutico a la jerarquía de valores presentes en las materias significantes pertinentes, del debate parlamentario como materialización de la oposición parlamentaria, entendida a su vez como campo discursivo (significaciones operantes), en el momento en el que se debatieron las dos leyes centrales de derechos en Argentina ya presentadas.

Los casos con los que se trabaja, como ya se dijo, están anclados en propuestas legales de ampliación de derechos vinculados con la ciudadanía comunicativa y sexual en Argentina. Dado que se posicionan como dos de las demandas que lograron tratamiento parlamentario, se propone abordar el debate parlamentario en torno a estos casos, y más concretamente, examinar los discursos esgrimidos por los legisladores que se manifestaron en contra de los proyectos de ley en el Congreso Nacional. 
Para la construcción del corpus de trabajo general, se tomaron las versiones taquigráficas de las sesiones de votación en ambas Cámaras Legislativas de las dos leyes observadas: ${ }^{10}$

1. Para el caso de la Ley 26522, la versión taquigráfica es la que se encuentra publicada por la Cámara de Diputados de la Nación, y que corresponde a la sesión del 16 de septiembre de 2009, así como la versión taquigráfica publicada por la Cámara de Senadores de la Nación correspondiente a la sesión especial de los días 9 y 10 de octubre de 2009.

2. Para el caso de la Ley 26618, se recuperó la versión taquigráfica publicada por la Cámara de Diputados de la Nación correspondiente a la sesión del 4 de mayo de 2010 y la versión taquigráfica publicada por la Cámara de Senadores de la Nación correspondiente a la sesión ordinaria de los días 14 y 15 de julio de 2010.

Con estos materiales, se inició un proceso de configuración del corpus analítico de trabajo. La distinción entre corpus general y corpus analítico se sostiene en la generación de operaciones orientadas al refinamiento paulatino del material discursivo, cuyo objetivo es la construcción de un corpus definitivo capaz de responder a las preguntas de investigación. Esto, en otras palabras, es la definición del discurso objeto de la investigación señalado por Verón (2013).

En este trabajo, se utiliza la denominación intervenciones como categoría operativa para designar a los discursos pronunciados por los legisladores que participaron como oradores (o tomaron la palabra) en cada una de las sesiones de votación de las Cámaras. Vale recordar que en el caso de la LSCA, durante la sesión de aprobación en la Cámara de

10. Las transcripciones han sido extraídas de las actas de sesión. Se remite al lector interesado a los archivos de cada Cámara, recuperables en: Diputados en //www.diputados.gov.ar/sesiones/sesiones/sesiones.html; Senado en http://www. senado.gov.ar/parlamentario/sesiones/tac

\section{8}


Diputados (16 de septiembre de 2009), las fuerzas políticas contrarias al proyecto decidieron no participar de la sesión legislativa por lo que, en principio, esta situación se traduce en una ausencia de datos (intervenciones). Sin embargo, como se dijo en su momento, las fuerzas políticas que se retiraron del recinto parlamentario no dejaron de poner de manifiesto su posición haciendo uso de la figura de moción de orden. Así, en este caso, frente a la ausencia de participación vía intervenciones, se consideraron las mociones de orden presentadas como parte del debate parlamentario en su calidad de materialidad discursiva.

Sobre esta base, se realizó una primera aproximación al material discursivo a partir de la identificación de las posiciones sostenidas por los legisladores en relación con el proyecto de ley en cada uno de los casos seleccionados. En el total de las intervenciones legislativas, se aplicó una tipología para identificar las posiciones frente al proyecto de ley en discusión. La tipología se basa en cuatro posiciones de enunciación (Guzmán, 2011): 1) a favor de la norma (sin dudas); 2) a favor de la norma (con dudas); 3) en contra de la norma (sin dudas) y 4) en contra de la norma (con dudas). En el caso particular de la ley de MI, el tipo 3 se combina con una categoría denominada a favor de proyectos alternativos, es decir, la categoría que comprende una posición legislativa en contra del matrimonio igualitario pero a favor de la sanción de otras figuras legales como la unión civil.

En este trabajo, se hizo foco en la oposición parlamentaria, por lo que el objetivo de esta primera aproximación fue seleccionar entre el total de intervenciones registradas aquellas que se pronunciaron en contra de las propuestas de reforma legal.

De este modo, se organizó el material textual, lo que dio por resultado:

1. Para el caso de la Ley 26522, veintidós mociones de orden (veintiuna se inscribieron como cuestiones de 
privilegio y una como solicitud de retorno del proyecto a comisiones legislativas) en Cámara de Diputados, y veinticinco intervenciones en Cámara de Senadores.

2. Para el caso de la Ley 26618, se seleccionaron veintiséis intervenciones en la Cámara de Diputados y veintidós en la Cámara de Senadores.

De esta manera, se construyó el corpus analítico definitivo, que quedó conformado por la totalidad de las noventa y cinco intervenciones de oposición (Tabla 5).

\section{Tabla 5. Corpus analítico}

Casos observados

Ley 26522

Ley 26618

Total de intervenciones por Cámara

Legislativa

Intervenciones del debate parlamentario (corpus analítico)
Intervenciones en debate parlamentario (en oposición)

Cámara de Cámara de

Diputados Senadores

22 25

26 22

48 47

Fuente: elaboración propia.

Con el corpus definitivo, se procedió a un proceso de lectura y relectura, identificación de persistencias e insistencias discursivas, y codificación y recodificación de pasajes textuales, con lo que se fue definiendo una estructura de nodos significativos a partir de los cuales se organiza la presentación del análisis en el próximo apartado.

Respecto a la exposición del corpus, es importante señalar que su reproducción completa en este artículo tomaría mucho espacio, por lo que se decidió realizar la presentación de los hallazgos del estudio con breves fragmentos ilus- 
trativos de las operaciones identificadas y de las apuestas interpretativas llevadas adelante.

Aun a riesgo de provocar trabas en la exposición (por la extensión de los datos citados), se consideró relevante mezclar fragmentos de las intervenciones legislativas de cada Cámara y de cada caso observado, esto con el ánimo de dar cuenta de la reiteración de las operaciones identificadas en los materiales analizados.

\section{Desplazamientos en las oposiciones parlamentarias}

La idea de desplazamientos, junto con la de condensación, tiene una rica historia en las ciencias sociales. Una posible genealogía de este concepto puede pensarse a partir del descubrimiento freudiano de los mecanismos de condensación y desplazamiento oníricos, que refieren a los medios principales que actúan en la desfiguración, en los sueños, de los deseos oníricos del inconsciente (Freud, 1991, pp. 285 y siguientes).

En esta línea, Lacan, en su Seminario 3, en las clases 17 y 18, dedicadas a metáforas y metonimias, señala la centralidad del significante en el análisis, puesto que en lo que Freud llama condensación y desplazamiento (y en la retórica, la metáfora y la metonimia), lo que se observa es un modo de ser de los significantes que expresan significados desaparecidos. Así también, por ejemplo, Benveniste (2001) plantea que la recuperación del descubrimiento freudiano es productiva para una comparación entre "la simbólica del inconsciente y ciertos procedimientos típicos de la subjetividad manifestada en el discurso" (p. 86); por su parte, Barthes (1972), entre estas operaciones, recupera la omisión, la condensación, el desplazamiento o la denegación.

En el campo del análisis político del discurso, Buenfil Burgos (1994) plantea una articulación entre psicoanálisis y hegemonía para que en el análisis se recuperen los reconocimientos de la multiplicidad presente en las operaciones de 
condensación y de la no fijación presente en las operaciones de desplazamiento. En palabras de la autora, el desplazamiento "alude a la circulación de un significado a través de diversos significantes [...], en el campo del análisis del discurso, [el desplazamiento] alude al tránsito, circulación, remisión, transferencia, paso de una carga significativa de un significante a otro" (Buenfil Burgos, 1994, p. 32). Este es el sentido con el que se recupera en este trabajo el concepto de desplazamiento.

El análisis de las intervenciones de la oposición parlamentaria argentina permitió identificar la emergencia de operaciones centrales a partir de las cuales se proponen dos categorías: 1) desplazamientos por fallas procedimentales y 2) desplazamientos por rencillas políticas. Como se expone en los apartados siguientes, estas categorías analíticas tienen en común y agrupan operaciones discursivas que cuestionan la institucionalidad democrática con base en factores externos a las leyes en discusión, objeto del debate parlamentario, y desplazan el eje de la discusión: la modificación de los marcos legales. Ahora bien, los desplazamientos también operan como fundamento de la posición de rechazo, y en esta dirección podrían pensarse como estrategia transversal al campo discursivo de la oposición parlamentaria.

\section{Desplazamientos por fallas procedimentales}

Una estrategia utilizada por la oposición parlamentaria durante el debate de las dos leyes fue colocar en escena pública los defectos del debate legislativo. Mediante denuncias sobre la ausencia de los requisitos necesarios para el cumplimiento -correcto, debido- de los procedimientos, se desplazó el tema del debate, se colocaron otros asuntos en foco, se dilató la sesión. En este sentido, se agruparon en esta categoría tres operaciones discursivas que emergen 
en la estrategia de oposición: 1) demarcación de errores técnicos, 2) denuncia de falta de tiempo y 3) improcedencia del asunto tratado.

\section{I. Demarcación de errores técnicos}

Polemizar respecto a los errores técnicos fue una operación que caracterizó el debate de la LSCA en la Cámara de Diputados. Como se mencionó, en esta sesión de votación, gran parte de los legisladores de bloques de oposición se retiró del recinto parlamentario sin participar de la discusión y votación. Las mociones de orden dan cuenta de la posición sostenida por los diputados de impugnar la legalidad de la sesión (y por tanto, anularla), utilizando para ello argumentos basados en los reglamentos de la Cámara, en concreto, como ya se dijo, en el artículo 26 del reglamento, en el que se establece el tiempo necesario para declarar nula la sesión parlamentaria (Honorable Cámara de Diputados de la Nación, 2014, p. 26).

En esta dirección, Riveros (2013) describe con mayor detalle las diferentes interpretaciones en torno al artículo 26 que utilizaron las diferentes facciones políticas del Parlamento para justificar su posición con el reglamento, aunque vale mencionar que el argumento de violación de régimen horario fue interpretado de diferente manera por los bloques de oposición en situaciones similares (previas y posteriores). ${ }^{11}$ Es decir, si en esta sesión los bloques de oposición esgrimieron la violación de régimen horario como fundamento para la suspensión, en otras ocasiones los mismos bloques solicitaron y avalaron la extensión de la tolerancia horaria: ${ }^{12}$

II. Por ejemplo, en la sesión convocada por la Coalición Cívica para el día 19 de marzo de 2009, en la cual se dio por anulada la sesión tras una tolerancia de cincuenta y nueve minutos (Riveros, 2013, p. 14).

12. Para las transcripciones utilizadas, se menciona inicial de nombre y apellido del diputado o senador, cargo, y las etiquetas SCA para los extractos provenientes de debates sobre la LSCA, y MI para los de la ley de matrimonio igualitario. 
(I) Esta sesión tiene una irregularidad en su origen, pues no se aplicó la norma que es de práctica en cuanto a que transcurrida media hora de la hora de citación se declara fracasada la sesión si no hay quorum. Ante cualquier planteo de constitucionalidad, esta sesión puede ser declarada nula. (P.Azcoiti, diputado, SCA)

(2) Media hora estricta es la que nos impone el reglamento para alcanzar el quorum. Siempre que se convoca a alguna sesión especial, transcurrida la media hora se la [sic] declara fracasada y se nos da la posibilidad de manifestarnos en minoría. (S. Giúdici, diputada, SCA)

Más allá de la confrontación entre los distintos bloques políticos sobre la interpretación correcta del reglamento y su aplicación al interior de la sesión parlamentaria, las intervenciones legislativas se presentaron como una estrategia dirigida a dilatar el tratamiento de la ley con el objetivo de suspender la discusión hasta que se efectuara la nueva composición del Parlamento. De hecho, los legisladores que se oponían al tratamiento de la LSCA en la Cámara también participaron en otras modalizaciones de lo público, insistieron en la ilegitimidad del tratamiento del proyecto y justificaron su posición con base en el recambio de la composición parlamentaria postelecciones legislativas (junio de 2009). En esa ocasión, el oficialismo perdió la mayoría en las Cámaras Legislativas, y desde los bloques de oposición se utilizó dicho cambio político como motivo para anular el debate hasta que no se conformara el nuevo Parlamento.

Ahora bien, sin duda, el espacio mediático es una de las modalizaciones centrales en las que se da la disputa pública, y es ahí también donde el argumento de ilegitimidad del debate aparece. Así, la sesión de la Cámara se trasladó a los medios de comunicación masiva cuando legisladores de la oposición justificaron ahí la suspensión del tratamiento en pos de la nueva composición parlamentaria: por ejemplo, el 27 de agosto de 2009, la senadora H. Duhalde aseguró en 
el canal TN que los oficialistas intentarían sacar todas las leyes antes de diciembre, mientras que el diputado electo $\mathrm{F}$. de Narváez señaló en el mismo canal, el 3 de septiembre del mismo año, que la ley debería tratarse en el nuevo Congreso. ${ }^{13}$

De este modo, esta estrategia se fortaleció con otras presentes en el espacio público (por ejemplo, la cobertura mediática del debate), como se analizó ya en un trabajo anterior (Guzmán, 2016). Son estrategias que reproducen el argumento de ilegitimidad del tratamiento mediante la participación activa de legisladores en medios de comunicación que brindaron estos fundamentos para el rechazo de la ley.

\subsection{Denuncia de falta de tiempo}

Caracterizar al debate como un proceso improvisado que no cumple con las debidas formas de un procedimiento democrático utilizando para ello el argumento de la falta de tiempo es otra operación recurrente de la oposición parlamentaria. Como se puede observar claramente en los ejemplos 3, 4, 5 y 6, el tiempo se evalúa como insuficiente, y por tanto se le resta profundidad a la discusión: como condicionante, la falta de tiempo y de profundidad en la discusión se posiciona como punto clave en el argumento opositor y opera al desplazar el tema de discusión para poner el foco en criterios de evaluación de los procedimientos institucionales:

(3) Considero que necesitamos un debate mucho más largo,y siento que hay señores diputados que piensan lo mismo. Ha habido una imposición, una presión de un sector, $y$ creo que tenemos que reflexionar sobre

I3. Una reconstrucción del tratamiento audiovisual en imágenes del recorrido del debate de la LSCA puede consultarse en Guzmán (2017). Allí se puede observar qué actores fueron invitados a comentar e informar sobre el proyecto de ley, lo que se sumó al encuadre recuperado por el medio de comunicación. Las referencias señaladas de Duhalde y De Narváez se encuentran en las páginas 29l y 317 del trabajo de Guzmán. 
esto. ¿Estamos dispuestos, por esa presión, a cambiar todo el sistema institucional de las familias y de los hogares? [...]. (C. Hotton, diputada, MI)

(4) Considero que se trata de un tema acerca del cual tendríamos que haber dado un debate mucho más profundo, serio, técnico, con tiempo y con la madurez que una sociedad democrática necesita. De haber procedido de esa manera, seguramente habríamos llegado a resolver o a enfrentar este tema mucho más fortalecidos y enriquecidos, y no con este sentimiento de la mirada esquiva, con el enojo que muchas veces generaron las discusiones que se dieron sin conocer en profundidad el tema. (M. Higonet, senadora, MI)

(5) Tengo derecho de disponer del tiempo físico para escribir mi posición y consultar con mi bloque qué posición vamos a adoptar frente a una cuestión determinada. Tengo derecho a oír a los ciudadanos que me votaron o que hayan manifestado interés por un tema sobre el cual nosotros tengamos que resolver [...]. En estas condiciones, no puedo ejercer mi representación popular como corresponde, es decir, con responsabilidad. En consecuencia [...], esto vicia el tratamiento de cualquier proyecto de ley. (F. Pinedo, diputado, SCA)

(6) Tanto la formulación extraparlamentaria del proyecto de ley como la formulación exprés de los debates formales que se llevaron a cabo (digo formales porque los argumentos no fueron escuchados ni tenidos en cuenta) dieron lugar a un dictamen que apareció con llamadas al costado, como si fuera un apunte universitario. Esos apuntes universitarios, que decían ser las modificaciones por los aportes de tantas horas de debate, en ningún momento incluyeron las opiniones de la oposición. (S. Giúdici, diputada, SCA)

Ambas discusiones de las leyes en cuestión también se encontraron relacionadas con la duda de si la sociedad (nombrada como el pueblo, la sociedad civil, etc.) estaba de acuerdo con las reformas legales. Es interesante en este punto remarcar que aunque integró el argumento de oposi- 
ción del parlamento, el sentido de la participación popular cambió en una y otra ley en discusión: mientras en el debate de la LSCA pareció desconocerse la participación de la sociedad civil, en el debate de ley de MI pareció demandarse esa misma participación.

Vale recordar que, como se señaló al principio de este trabajo, en ambos casos hubo instancias de participación pública abiertas a la ciudadanía. Aun así, es necesario mencionar también que ambas instancias participativas difirieron en su complejidad, por ejemplo, en relación al nivel de participación, a los tiempos programados para su realización, las formas de organización, la cantidad de lugares en los que se realizaron, los actores involucrados en su implementación, entre otras dimensiones que dan cuenta de las diferencias formales e informales, cualitativas y cuantitativas, etc., que separaron a ambas instancias. Excede los objetivos de este trabajo desarrollar con mayor precisión estas dimensiones.

En el argumento de oposición a la LSCA, estas instancias de participación de la sociedad civil se incluyeron en los argumentos subordinadas a los mecanismos formales necesarios para validar esa participación. Aquí un par de ejemplos:

(7) Si bien es interesante la iniciativa de discutir en los foros, se pretendió, con un claro rasgo autoritario, sustituir la institución Congreso por el debate en la sociedad [...]; me parece fantástico ese mecanismo de participación popular, pero ¡cuidado!, porque cuando sustituye, elimina, ningunea o desconoce al Congreso, estamos frente a una reacción autoritaria [...]. Desde ningún punto de vista podemos hoy, sin debate, sin discusión, sin reconocer los mecanismos institucionales lógicos de la sanción de una ley (en este caso, una ley estratégica), rubricar-como si este Congreso fuese una escribanía- un proyecto de ley que seguramente podría ser mejorado en forma sustancial con el aporte que todos podemos hacer. (G. Baldata, diputada, SCA) 
(8) [...] todos tienen derecho a opinar, pero [...] la tarea de legislar, de elaborar las leyes, era del Parlamento; que nosotros teníamos la obligación de escuchar todas las voces, pero también teníamos la obligación de ejercer nuestra tarea con responsabilidad; [...] ninguno de los que había participado tenía la obligación de conocer cómo se elaboraba un proyecto de ley y cuál era el impacto que iba a tener en la sociedad si nos equivocábamos o no. (N. Pinchetti de Sierra Morales, senadora, SCA)

Por su parte, en el debate sobre la ley de MI, el argumento de oposición respecto a la participación de la sociedad civil apareció como una demanda de los legisladores, principalmente en conexión con la consulta popular y con el mandato legislativo. Se puede constatar, incluso, que esta operación en este caso se conectó con algunas variantes vinculadas al avance del proyecto en las Cámaras Legislativas. Por ejemplo, las audiencias públicas, como instancias de participación, se desarrollaron a solicitud de la CLGS, lo que significa que se hicieron luego de la votación de los diputados y antes de la de los senadores. Una consulta popular, como se ve en el ejemplo 9, apareció como demanda de los legisladores, principalmente durante la sesión parlamentaria en la Cámara de Diputados, mientras que el argumento de ausencia de mandato apareció principalmente en la sesión de los senadores. Por último, vale mencionar que algunos legisladores presentaron de manera formal proyectos de solicitud de consulta popular. ${ }^{14}$

(9) Lo que estamos tratando no es una cuestión menor ni de forma. Es importante que hayamos dado este debate, porque se está propiciando la modificación de la institución matrimonial. Tan importante es, que

14. Por ejemplo, en la Cámara de Diputados, ingresaron dos expedientes: uno solicitando la realización de consulta popular vinculante, firmado por $\mathrm{C}$. Hotton, de Valores para mi País, Buenos Aires, y uno de consulta popular no vinculante, firmado por O. De Marchi, del partido Demócrata de la provincia de Mendoza. 
hubiese sido conveniente someterlo a consulta popular en el ámbito de la sociedad argentina. (N. Erro, diputado, MI)

(I0) Como este tema no está en nuestra plataforma partidaria ni ha sido, al menos en muchos casos, ningún compromiso electoral, traté de buscar el fundamento de mi voto en lo que es nuestro credo, en nuestra profesión de fe doctrinaria. (M. Cimadevilla, senador, MI)

Relacionado con la falta de tiempo (necesario para dar un debate legítimo), la oposición parlamentaria también utilizó la idea de consenso como una máxima de medida de la calidad o validez de los debates legislativos (y del reconocimiento de derechos) en contraposición con lo conflictivo. Dicho de otro modo, se desplazó el eje del debate hacia el señalamiento de la conflictividad imperante en el contexto del debate parlamentario. La confrontación/división social sirvió para fundamentar la oposición, y en tanto se asumió que los proyectos de reforma legal no poseían el consenso social necesario, la responsabilidad de la decisión (voto) se trasladó a la falta de acuerdo.

Para los legisladores, un colectivo queda opacado por el clima confrontativo y, en orden del correcto procedimiento democrático, es necesario reconocer a este colectivo construido como la sociedad, el pueblo, los argentinos (más allá de los intereses de los sectores implicados en las disputas). Así, en el caso del debate de la ley de MI, el desplazamiento hacia un contexto de confrontación inadecuado para la sanción de las leyes expuso los defectos del procedimiento legislativo y señaló los requisitos ausentes para el funcionamiento de un -verdadero- debate democrático:

(II) Este proyecto debería ser la ley de todos y del consenso, a partir de una política de Estado para todos los argentinos. Que se la [sic] saque de atropello $y$ a las apuradas me parece que es absolutamente incorrecto. Creo que es hora de que terminemos de degradar al Parla- 
mento. Dejemos que corran los tiempos y sancionemos las leyes como corresponde. (C. Urlich, diputado, SCA)

(I2) [...] con la unión civil podría haberse encontrado un camino de consenso y de respeto que, en vez de dividir a sectores del pueblo argentino fundamentalistas -que sólo quieren crispar y dividir-, los uniera. (A. Rodríguez Saá, senador, MI)

\subsection{Improcedencia del asunto tratado}

Entre los desplazamientos por fallas procedimentales, la comparación aparece como otra operación estratégica que se utilizó para evaluar la relevancia del proyecto tratado en las sesiones legislativas mediante una jerarquización de asuntos sociales más o menos urgentes, más o menos pertinentes. La evaluación de la pertinencia o impertinencia del tema debatido en las sesiones legislativas asumió de esta manera el carácter de suficiencia para fundamentar el rechazo, más allá de las características puntuales de los derechos que se pusieron en discusión para ambas leyes.

Algunas de las significaciones puestas en escena por la oposición parlamentaria buscan evidenciar la improcedencia legislativa atribuyéndoles a los promotores de las propuestas una actitud que negaba la existencia de los problemas vinculados a la seguridad y la pobreza. Con todo, la impertinencia temática en los debates desplazó los ejes centrales de los proyectos en discusión. Los siguientes ejemplos ilustran algunas de las insistencias en estas operaciones:

(I3) El pueblo no estaba clamando por tener una participación en la palabra, sino en la comida, en el techo propio, en el trabajo y en la dignidad. Pero no estamos haciendo nada por ellos, y eso sigue empeorando en la Argentina. (M. Cabanchik, senador, SCA)

(14) Si hiciéramos una encuesta en cualquier barrio o ciudad, ¿cree que alguien le va a decir que la prioridad que tiene en su vida cotidiana es 
la radio FM o AM que le sacarán o instalarán, o el canal con el que hace zapping? El tema es la pobreza, la desocupación, la inseguridad, el flagelo de la droga. (C. Rossi, senador, SCA)

(I5) Hoy es el matrimonio homosexual, mañana es otra cosa, porque no tenemos proyecto de país, y son cientos de horas las que perdemos acá sin ocuparnos seriamente de los temas de la gente [...]. En el Senado se ha votado dictamen mayoritario por el [Instituto Nacional de Estadística y Censos] INDEC, por el $82 \%$ móvil.Vamos avanzando en algunos puntos. Ahora, el Gobierno ha manifestado que el $82 \%$ no se puede dar; mientras tanto, se roban todo lo que pueden y la gente sigue sin tener garantizados sus derechos. (H. González de Duhalde, senadora, MI)

(I6) Además, señalo que hubiera querido que hoy en este recinto se estuviera discutiendo primero acerca de aquellas desigualdades escandalosas en el orden de lo económico, lo social y lo político, a saber, señor presidente, crecimientos patrimoniales injustificables, obturación de la palabra y clausura del diálogo, corrupción extrema y generalizada, clientelismo denigrante y dadivoso, pauperización, indigencia cultural, etcétera. Todo ello opuesto a la equidad, a la paz, a la justicia social y a la dignidad de las personas. (B. Monllau, senadora, MI)

\section{Desplazamientos por rencillas políticas}

Otra estrategia utilizada por la oposición parlamentaria es la que se definió como desplazamientos por rencillas politicas, y que se asienta, de manera fundamental, en la constatación de que los debates por la LSCA y por la ley de MI se desarrollaron en un contexto de disputas políticas que evidentemente atravesaban el espacio legislativo y adquirían su lugar en la oposición parlamentaria.

En este sentido, mediante ciertas caracterizaciones de actores y prácticas vinculadas al tratamiento de las leyes como indeseables, se desplaza el debate sobre estas. De esta 
manera, a partir de la asignación de características negativas y modos incorrectos de actuar, se habilita el rechazo a los tratamientos legislativos por fuera de la argumentación en torno a los contenidos propios de los proyectos en sí mismos. Se agrupan en esta categoría dos operaciones fundamentales: 1) construcción de un ellos negativo, y 2) caracterización del debate como una pelea ajena.

\section{I. Un ellos negativo}

En el marco de una mirada enunciativa, otra de las operaciones de la oposición parlamentaria es la construcción de líneas demarcatorias de un nosotros y un ellos a partir de las que se fundan estrategias argumentativas de desplazamiento del debate sobre las leyes. El argumento de oposición construyó una serie de atributos negativos con los que definió al sistema democrático argentino (ejemplo 17), y en este sentido, el uso de ejemplos de debate legal en otros países sirvió como marco para mostrar las distancias cualitativas entre la argentina y otras democracias contemporáneas (ejemplos 18, 19 y 20).

Verón (1987) señala que la enunciación política "parece inseparable de la construcción de un adversario" (p. 16), y que en el juego enunciativo se configura un desdoblamiento en la destinación mediante la creación de un otro negativo y un otro positivo que funcionan como lo que el propio autor define como prodestinatarios y contradestinatarios del discurso político.

Si bien este fenómeno se puede observar de manera clara en la estrategia de desplazamiento, es posible sostener que la lógica se extiende más allá de los límites institucionales de enunciación en la recuperación del desdoblamiento o de las caracterizaciones del otro negativo, por fuera de las puertas del Parlamento o las palabras del parlamentario. Ya en otros trabajos se constata la constitución de estas figuras enunciativas en el discurso de la cultura bajo la 
forma de mitos decadentistas (Grimson, 2013) o de las manifestaciones callejeras en resistencia a la ampliación de derechos (Sgró Ruata, 2011).

(17) Esta iniciativa tiene un problema originado en otra viveza criolla, porque más allá de todos los grandes aciertos de esta norma que aquí se expone, tuvimos hace un tiempo atrás, en este recinto, la decisión de adelantar elecciones, en una típica jugada de la opaca viveza criolla argentina. (A. Rached, senador, SCA)

(18) Mientras tanto, porque siempre es bueno levantar la vista y mirar hacia otros lados, otros países eligen modelos diferentes; así les va y así nos va a nosotros. (E. Sanz, senador, SCA)

(19) El régimen legal del casamiento y adopción de personas del mismo sexo ha sido debatido en muchos países del mundo, aunque no ha sido aprobado en la gran mayoría de ellos. El conjunto mayoritario de las naciones desarrolladas de la Tierra todavía no ha dado curso a este régimen. (M. Morejon, diputado, MI)

(20) Solamente en ocho países del mundo está legislado el matrimonio homosexual. ¿Qué quiere decir esto? Sinceramente, esto me llama la atención, porque si estamos hablando de que esta iniciativa va a traer cultura y vamos a estar a la vanguardia, ipor qué algunos países europeos o los Estados Unidos aún no han legislado en este sentido? (M. Gallardo, diputada, MI)

Las caracterizaciones negativas encontraron como destinatarios a los promotores de los proyectos de ley. Estos contradestinatarios fueron visibilizados de múltiples maneras, es decir, mediante diferentes nominaciones (o afrentas, como en el ejemplo 22), aunque se condensaron en remisiones al Gobierno en ejercicio: la presidenta, el oficialismo, el bloque oficialista, etc. 
(2I) [...] en lugar de tratar una ley de medios como se debe, creo que el oficialismo, en esto, ve en la norma una herramienta para consolidar un modelo hegemónico, que no es lo mismo, que no es menor, acallando voces. (C. Marino, senador, SCA)

(22) No es la primera vez que este imitador de Maquiavelo que tenemos en el Gobierno nos pone en situaciones extremas en temas que no son poco importantes, son muy importantes, pero no son urgentes. $(H$. González de Duhalde, senadora, SCA)

(23) Nuevamente, el oficialismo nos lleva al tratamientos exprés, al todo o nada, a la división de la sociedad, como si en eso hubiera algún rédito político. (S. Escudero, senadora, MI)

(24) Hay legisladores y legisladoras del bloque oficialista para quienes, a partir de la expresión del presidente del [Partido Justicialista] P], esto pasó a ser un tema de alto interés personal o partidario. Me pregunto por qué no están acá: habrían sufrido insinuaciones, pedidos u órdenes para no hacerse presentes. No me voy a extender mucho en esto porque casi siempre refiero a la debilidad o renguera de nuestro sistema democrático. (A.Vera, senador, MI)

En este sentido, el desplazamiento del objeto en discusión y la operación de justificación de la propia posición se complementaron con la descalificación de los promotores del proyecto de ley. En la construcción de un ellos, la estrategia de oposición parlamentaria depositó un disvalor ético: a quienes promueven las reformas legales se les adjudicó una incapacidad para sostener iniciativas de ampliación de derechos, dada la ilegitimidad de origen de estas iniciativas:

(25) Todo es justificado si lo anoto como instrumentos de la concentración de poder. Ahí todo se justifica, todo se armoniza. Pero lo que le pediría al oficialismo es que no lo haga hipócritamente, que de una vez asuma que lo que le interesa con este proyecto es concentrar el

\section{4}


poder sobre los medios para pensar que sigue concentrando el poder en la realidad. (M. Cabanchik, senador, SCA)

(26) Si estamos tan en contra de los oligopolios, ¿por qué votaron la ley que votaron en enero de 2002 ? $^{15}$ (L. Negre de Alonso, senadora, SCA)

(27) ¿Qué ha hecho este Gobierno para poner freno a la acumulación y a los monopolios? Algunos dirán que no contaban con las herramientas. No, presidente; no lo quiso. (C. Petcoff Naidenoff, senador, sCA)

(28) Pero ya que hablamos de que se trata de una ley antimonopolios, no podemos dejar de señalar que si los monopolios existen es porque este Gobierno quiere que existan, ya que este tiene las herramientas legales para combatir los monopolios o las posiciones dominantes, depende cómo se los [sic] quiera denominar, pero no sólo que no las utiliza sino que, además, instrumentó normas para fomentar las actividades dominantes o monopólicas. (C. Marino, senador, sCA)

(29) Lamentablemente, este debate, que es un tema que debería unirnos y no diferenciarnos, se da en un clima político que no puedo dejar de analizar, donde la propia presidenta de la república y su marido también utilizan este asunto para crispar y dividir a la sociedad. (M. Cimadevilla, senador, MI)

(30) Hasta hace unas horas, tenía la ilusión de que quienes decían desde el oficialismo que la norma debiera salir como ellos querían, o si no caía todo, que reflexionaran y se dieran cuenta de que no debería estar permitido jugar al todo o nada. (A.Vera, senador, MI)

15. Negre de Alonso se refiere en este pasaje a la modificación realizada en enero de 2002 a la Ley de Quiebras (Ley 25563), por la cual, en el marco de la crisis económica y social de $200 \mathrm{I}$, se suspendía provisoriamente la posibilidad de los acreedores de recurrir a la justicia en el caso de que se incumplieran las obligaciones de las empresas deudoras. La referencia cobra sentido en el marco del debate a partir de que una de las empresas beneficiadas por dicha ley en su momento fue el Grupo Clarín. Sobre este asunto, ver:Mastrini, Becerra, Baranchuk y Rossi (2005) o Bitonte (20II). 
Con la intención de caracterizar operaciones estratégicas de la oposición parlamentaria, interesa también resaltar la introducción de la idea de afectación del proceso, esto es, la consideración de que el proceso formal establecido para la sanción de una norma jurídica se ve afectado en tanto es producto de una política de división de sectores (ejemplo 29). Mediante este mecanismo, se construye la idea de que los procesos de debate están sometidos a la presión de sectores que conducen a claudicar ante la pretensión de su dominación hegemónica, como sucedió en el caso de la LSCA (ejemplos 25 a 28), o la lógica del todo o nada, en el caso de la ley del mi (ejemplo 30).

En suma, el nosotros delineado desplazó la discusión concreta aduciendo la falta de legitimidad para llevar adelante las normas en discusión. En este sentido, los significantes Cristina Kirchner, Néstor Kirchner, Gobierno u oficialismo aparecieron como un mecanismo de condensación de las atribuciones de lo negativo argentino.

\subsection{Luchas ajenas}

Otra de las operaciones utilizadas por la oposición parlamentaria fue fundamentar su posición (rechazo) frente a los proyectos de ley en discusión en un afuera marcado por actores en pugna. Así, distintas disputas existentes en el contexto político social del debate parlamentario fueron recuperadas por el discurso de oposición para ser colocadas como corruptoras del proceso legislativo, en tanto involucraban sectores con intereses particulares, alejados del interés común que deberían defender el Estado y los legisladores.

De ello, resulta que al debate parlamentario se le adjudicó una precariedad, explicada por su alejamiento de la voluntad popular -requisito para la sanción de leyes en resguardo del bien común-. Las rencillas entre actores ajenos a las Cámaras Legislativas desplazaron así el tema específico del debate, colocaron en escena los intereses sectoriales en 
pugna, y buscaron anular el debate parlamentario con argumentos basados en la inexistencia de un interés legítimo.

De este modo, y como se expone a continuación (en los ejemplos 31 a 33), cobraron relevancia operaciones argumentativas utilizadas por los legisladores para fundamentar el rechazo a los proyectos en discusión con base en factores externos al asunto que se estaba debatiendo. Si se toma en consideración que cada una de las leyes colocaba en debate público asuntos diferentes y afectaba intereses diferentes, a los fines de este trabajo se resaltan aquellos puntos comunes que sirven para caracterizar la estrategia de oposición parlamentaria.

Por ejemplo, en las sesiones legislativas para la LSCA, la configuración de rencillas políticas entre actores ajenos a las Cámaras se construyó principalmente en relación al Gobierno y el Grupo Clarín. El primero refiere al arco político denominado kirchnerista, y el segundo refiere al conglomerado de medios más importante de Argentina -y uno de los más importantes de la región-(Becerra, Marino, y Mastrini, 2012, p. 77). En el caso de la ley del Mi, la confrontación ingresó principalmente desde el enfoque de cruzada del Gobierno contra la Iglesia católica.

Aunque el enfrentamiento entre sectores (Gobierno-Clarín y Gobierno-Iglesia católica) fue colocado discursivamente afuera de lo propio de las Cámaras Legislativas, como un litigio ajeno, al mismo tiempo fue señalado como condicionante del debate parlamentario:

(3I) Quiero dejar bien en claro que entiendo perfectamente que estamos inmersos en esta sesión maratónica porque se ha montado un ring público, donde en un extremo está el expresidente Néstor Kirchner y, en el otro, el diario Clarín [...]. No quiero que, en nombre de una pelea de la que no somos parte, se avance sobre derechos fundamentales que tenemos todos los argentinos, tales como los de opinar y publicar nuestras ideas por la prensa sin censura previa, de circular libremente 
sin tener que mirar a los cuatro costados para verificar que no haya nadie siguiéndonos o inventándonos campañas descalificantes en nuestra contra [sic]. (N. Pinchetti de Sierra Morales, senadora, SCA)

(32) Primero, fue la lucha contra el campo, después fue la lucha contra Clarín, y ahora parece que es la lucha contra la Iglesia.Y los derechos de los que estamos hablando y los derechos de los niños parece que a nadie le importan. (S. Escudero, senadora, MI)

(33) Lo mismo nos pasó con la discusión y la pelea personal del Gobierno con Clarín. Ahora se trata de la pelea personal del Gobierno con la Iglesia.Y la verdad es que yo no quiero mirar esto desde el punto de vista religioso, pero creo sinceramente que estamos dejando de analizar un tema que es trascendente para la sociedad argentina [...]. (H. González de Duhalde, senadora, MI)

En ambos casos, la operación argumentativa sirvió de enclave para solidificar la posición de rechazo a las leyes con base en la existencia de un clima confrontativo que perturbaba el interés general. De esta manera, al ubicar el debate en un marco que lo trascendía o condicionaba (esto es, la confrontación político-sectorial materializada en Gobierno contra Clarín y Gobierno contra Iglesia católica), la oposición parlamentaria trasladó los fundamentos de rechazo a factores externos (enmarcados a su vez como condicionantes de decisión).

En este sentido, el desplazamiento del asunto tratado respondió a una operación estratégica de la oposición en pos de justificar la decisión de rechazo adoptada frente a las leyes en un marco de tensiones (un afuera parlamentario). De este modo, el enmarque operó funcionalmente no sólo para la posición sostenida en el debate parlamentario, sino también hacia el campo de fuerzas y tensiones políticas en las que ese debate se inscribía. 


\section{Conclusiones}

En este trabajo, se analizaron estrategias discursivas de oposición parlamentaria en dos debates que politizaron la ciudadanía sexual y comunicativa en términos de ampliación de derechos en Argentina. Considerando que avanzar en la compresión del papel de la oposición en el juego político democrático forma parte de la problematización de la calidad democrática, el estudio se enfocó en el Poder Legislativo argentino como una de las instituciones formales sustanciales de la democracia representativa.

En concreto, se atendió el debate parlamentario tomándolo como momento de observación clave, esto es, como instancia singular donde la oposición se materializa (se hace argumento, se visibiliza) en tanto se aborda la oposición parlamentaria como un campo discursivo (significaciones puestas en la escena pública). De este modo, se identificó aquello que emerge como común, puntos o anclajes, a partir de una lectura transversal de las intervenciones legislativas en el Congreso nacional. Esto condujo a advertir que el desplazamiento del asunto (modificación de los marcos legales) es un componente que adquiere centralidad en la oposición parlamentaria.

Sobre esta base, se propusieron dos categorías analíticas que agrupan operaciones discursivas presentes en la oposición parlamentaria y que buscan captar el fenómeno en términos de desplazamientos. Así, las categorías desplazamientos por fallas procedimentales y desplazamientos por rencillas politicas se utilizaron para caracterizar estrategias, mientras se entendió a la oposición como un campo discursivo y al debate parlamentario como materialización de significaciones articuladas en la escena pública.

La primera categoría, desplazamientos por fallas procedimentales, agrupa operaciones discursivas relacionadas con la demarcación de errores técnicos, denuncia por falta 
de tiempo (y profundidad) de la discusión, e improcedencia del asunto tratado. La segunda, desplazamientos por rencillas políticas, agrupa aquellas operaciones discursivas relacionadas con la construcción de un campo de disputa (nosotros/ellos) y el enmarque del debate como producto de una pelea ajena al cuerpo parlamentario. Ambas procuran dar cuenta de los modos en que el eje central del debate (modificación de los marcos legales) fue desplazado por el cuestionamiento de la institucionalidad democrática, con base principalmente en factores externos.

Estos desplazamientos, al mismo tiempo, atravesaron el campo discursivo de la oposición parlamentaria argentina como fundamento de la posición de rechazo sostenida frente a los proyectos de ley y, en este sentido, las estrategias discursivas usadas pueden ser entendidas como dirigidas a clausurar el debate. En suma, estas estrategias de oposición parlamentaria utilizaron, para desplazar el eje de la discusión y la responsabilidad frente a los proyectos de ley, el supuesto de mal funcionamiento de los procesos democráticos (vía el uso de figuras del procedimiento formal dispuestas para justificar la oposición) y el supuesto de entornos inapropiados de convivencia democrática.

La oposición parlamentaria invirtió así los términos del debate (o los desfiguró): canalizó el rechazo a la ley no en relación con el tema debatido (reforma legal), sino en nombre del resguardo de las instituciones democráticas. Esta estrategia activó una lógica que permitió instalar sospecha sobre el Parlamento y, paradójicamente, en nombre de velar por lo democrático del proceso, utilizó la intervención o participación para intentar inhabilitar el debate parlamentario al desplazar el objeto de discusión.

Más aún, este desplazamiento podría pensarse en referencia a que, frente al objeto mismo (ampliación de derechos), la oposición se presentó indecible. Por ello, es posible conjeturar que más que característica del discurso 
parlamentario-político, esta posición se puede pensar como característica de una configuración conservadora o, en un nivel más profundo, como modo de ser de una escisión originaria de nuestras sociedades asentadas en formas de discriminación por raza, clase y género.

De acuerdo con Dahl (1989) el debate se define como el "hacer [de] alguna cosa objeto de discusión, controversia o litigio" (p. 19). Pues bien, para finalizar, cabe dejar planteado si el fenómeno de los desplazamientos de los objetos de discusión en el debate parlamentario entorpece el fortalecimiento de los sistemas democráticos, en contraposición con aquello que, en principio, parecería perseguir.

Altman, D.,y Pérez-Liñán,A. (200I).Assessing the Quality of Bibliografía Democracy: Freedom, Competitiveness and Participation in Eighteen Latin American Countries. Democratization, 9(2), 85-100. doi https://doi.org/I0. I080/7|4000256 Bajtín, M. (1997). Estética de la creación verbal. México: Siglo XXI.

Barrientos del Monte, F. (20I5) La oposición política: notas para una discusión teórica. Debates, 9(3), I43-164. doi https://doi.org/ I 0.22456/ / 982-5269.490I2

Barthes, R. (1972). Crítica y verdad. Buenos Aires: Siglo XXI. Bayley, P. (ed.) (2004). Cross-Cultural Perspectives on Parliamentary Discourse. Ámsterdam: John Benjamins Publishing Company. doi https://doi.org/I0.1075/dapsac. 10

Becerra, M., Marino, S., y Mastrini, G. (20I2). Los medios digitales:Argentina. Londres: Open Society Foundations. Recuperado de https://www.opensocietyfoundations. org/sites/default/files/mapping-digital-media-argentina-spanish-20I30424.pdf

Benveniste, E.(200I). Problemas de lingüística general. México: Siglo XXI.

Berdondini, M. (2016). Democratización y contextos de discusión: lo litigioso de los derechos de comunicación 
y sexualidades en dos "leyes candentes" de la política argentina. Pilquen, 19(I), 42-54. Recuperado de http:// www.scielo.org.ar/pdf/spilquen/v I 9n I/v I 9n la04.pdf

Biglieri, P. (20I3). Emancipaciones. Acerca de la aprobación de la ley del matrimonio igualitario en Argentina. Íconos, (46), I45-I60. Recuperado de http://www.redalyc.org/ articulo.oa?id=509263350 10

Bimbi, B. (2010). Matrimonio igualitario. Intrigas, tensiones y secretos en el camino hacia la ley. Buenos Aires: Planeta.

Bitonte, M. E. (20II). Interacción, intervención, televisión. Transformaciones de la mediatización de la política en la era kirchnerista. Ciencias sociales. Revista de la Facultad de Ciencias Sociales, UBA, (78), 93-99.

Bitonte, M.E.,y Dumm, Z. (2007). El discurso parlamentario: ¿diálogos en la torre de Babel? En R. Marafioti (ed.), Parlamentos (pp. 169-195). Buenos Aires: Biblos.

Bonetto, M. S., y Martínez, F. (comps.) (20I2). Política y desborde. Más allá de la democracia liberal.Villa María: Eduvim. Buenfil Burgos, R. N. (1994). Cardenismo: argumentación y antagonismo en educación. México: Departamento de Investigaciones Educativas, Centro de Investigación y de Estudios Avanzados del IPN.

Cabrera, D. (2006). Lo tecnológico y lo imaginario: las nuevas tecnologías como creencias y esperanzas colectivas. Buenos Aires: Biblos.

Caletti, S. (200I). Siete tesis sobre comunicación y política. Diálogos de la comunicación, (63), 37-49.

Caletti, S. (2006). Decir, autorrepresentación, sujetos. Tres notas para un debate sobre política y comunicación. Versión, (17), 19-78.

Caletti, S. (2007). Repensar el espacio de lo público. Un esbozo histórico para situar las relaciones entre medios, política y cultura. Boletín de la Biblioteca del Congreso de la Nación, (I23), 195-252. 
Carbó,T. (1993). “Nosotros, que nos quisimos tanto...”. La escena discursiva en la Cámara de Diputados. Discurso. Teoría y análisis, (14), 69-95.

Castoriadis, C. (2007). La institución imaginaria de la sociedad. Buenos Aires: Tusquets.

Clerico, L., y Aldao, M. (20 I0). Matrimonio igualitario. Perspectivas políticas y jurídicas. Buenos Aires: Eudeba.

Dahl, R. (1 989). La poliarquía. Participación y oposición. Madrid: Tecnos.

Delamata, G. (20I3). Movimientos sociales, activismo constitucional y narrativa democrática en la Argentina contemporánea. Sociologías, (32), 148- I80. doi http://dx.doi. org/I0.1590/SI5I7-452220I3000100007

Delamata, G. (20I4). Transformaciones del campo social activista y cambio democrático en Argentina. Lasaforum, XIV(I), 9-12. Recuperado de https://forum.lasaweb.org/ files/vol45-issue I/Debates4.pdf

Diamond, L., y Morlino, L. (2004). The quality of democracy. An overview. Journal of democracy, 15(4), 20-31.

Fraser, N. (1997). Justitiainterrupta: reflexiones críticas desde la posición "postsocialista". Bogotá: Siglo del Hombre Editores.

Freud, S. (1991). Obras completas. Volumen 4 (1900). La interpretación de los sueños (primera parte). Buenos Aires: Amorrurtu.

Grimson, A. (20I3). Mitomanías argentinas. Cómo hablamos de nosotros mismos. Buenos Aires: Siglo XXI.

Guzmán,V.H.(20I I). El proceso de disputa en torno a la Ley de Servicios de Comunicación Audiovisual en Argentina (2009). Derecho a comunicar, (I), 18-34. Recuperado de https://biblat.unam.mx/es/revista/derecho-a-comunicar/3

Guzmán,V.H.(20I2). Ciudadanía comunicativa en Argentina. Los Foros Participativos de Consulta Pública sobre la propuesta de proyecto de Ley de Servicios de Comuni- 
cación Audiovisual. Question, I (33), I 70- I83. Recuperado de https:/perio.unlp.edu.ar/ojs/index.php/question/ article/view/I 342

Guzmán, V. H. (20I6). Una "ley de medios" en los medios. La Ley de Servicios de Comunicación Audiovisual argentina en el espacio público mediatizado. Estudios del mensaje periodístico, 22(2), 334-364. doi http://dx.doi. org/I 0.5209/ESMP.54249

Guzmán,V.H.(20I7). El relato audiovisual de la ley de medios K.Todo Noticias y el proyecto de Ley de Servicios de Comunicación Audiovisual (Argentina, 2009). Razón y palabra, (98), 286-367. Recuperado de http://www. revistarazonypalabra.org/index.php/ryp/article/view/947 Honorable Cámara de Diputados de la Nación (26 de mayo de 2008). Declaración de interés. Expediente:265 I-D-2008. Trámite parlamentario $n^{\circ} 52$. Buenos Aires: Honorable Cámara de Diputados de la Nación.

Honorable Cámara de Diputados de la Nación (20l4). Reglamento de la Honorable Cámara de Diputados de la Nación.Argentina: Dirección de Información Parlamentaria, Honorable Cámara de Diputados de la Nación Argentina.

Honorable Senado de la Nación (20I0). Versión taquigráfica de las audiencias públicas llevadas adelante por la Comisión del Legislación General del Senado en las provincias de Córdoba, San Juan, Jujuy, Tucumán, Chaco, Corrientes. Buenos Aires: Honorable Senado de la Nación.

lonescu-Ruxăndoiu, L. (20I2a). Introduction. En L. lonescu-Ruxăndoiu (ed.), Parliamentary Discourses Across Cultures (pp. I-22). Newcastle: Cambridge Scholars Publishing. lonescu-Ruxăndoiu, L. (ed.) (20I2b). Parliamentary Discourses across Cultures. Newcastle: Cambridge Scholars Publishing.

La Serna, C. (20I5). Los imaginarios estatales bajo la experiencia kirchnerista. Córdoba: IIFAP-UNC. 
Marafioti, R. (ed.) (2007). Parlamentos. Buenos Aires: Biblos. Martín, L. (20II). Giro judicial y legitimidad pública en la política argentina. En I. Cheresky (comp.), Ciudadanía y legitimidad democrática en América Latina (pp. 363-393). Buenos Aires: Prometeo.

Mastrini, G., Becerra, M., Baranchuk, M., y Rossi, D. (2005). Introducción. En G. Mastrini (ed.), Mucho ruido, pocas leyes. Economía y políticas de comunicación en la Argentina (1920-2004) (pp. I I-28). Buenos Aires: La Crujía.

Morlino, L. (20I2). Observando las diferentes calidades de la democracia. Revista mexicana de análisis político y administración pública, I ( I), 9-48. Recuperado de http:// www.remap.ugto.mx/index.php/remap/article/view/2

Natalucci, A. (20l I). Entre la movilización y la institucionalización. Los dilemas de los movimientos sociales (Argentina, 200I-2010). Polis, 10(28), 193-219. doi http:// dx.doi.org/I0.4067/S07I8-656820II000I000I 2

Pérez, G., y Natalucci, A. (20I2). El kirchnerismo como problema sociológico. En G. Pérez, y A. Natalucci (eds.), "Vamos las bandas". Organizaciones y militancia kirchnerista (Pp. I-19). Buenos Aires: Nueva Trilce.

Retamozo, M. (20II). Movimientos sociales, política y hegemonía en Argentina. Polis. Revista latinoamericana, 10, I-3I. Recuperado de https://journals.openedition. org/polis// 249

Riveros, P. (20I3). Concepciones y prácticas delegativas en los partidos de oposición [ponencia presentada en las $X$ Jornadas de Sociología]. Facultad de Ciencias Sociales, Universidad de Buenos Aires: Buenos Aires. Recuperado de http://cdsa.aacademica.org/000-038/432

Rodríguez, C. (20I5). La actividad legislativa de la oposición parlamentaria en las legislaturas subnacionales argentinas. Revista uruguaya de ciencia política, 24(I), 23-45. Recuperado de http://www.scielo.edu.uy/pdf/rucp/ v24nl/v24nla02.pdf 
Bibliografía

Rodríguez Villafañe, M.J. (2009). Los fines justifican los medios. Buenos Aires: Paraná.

Sgró Ruata, C. (20I I). Prácticas públicas políticas. Marchas y movilizaciones conservadoras en torno al matrimonio entre personas del mismo sexo. En M.A. Peñas Defago, y J.M.Vaggione (comps.), Actores y discursos conservadores en los debates sobre sexualidad y reproducción en Argentina (pp. 163-198). Córdoba: Ferreyra.

Solari, N.,y Von Opiela, C. (20I I). Matrimonio entre personas del mismo sexo. Ley 266/8: antecedentes, implicancias, efectos. Buenos Aires: La Ley.

Stoessel, S. (20|4). Giro a la izquierda en la América Latina del siglo XXI. Revisitando los debates académicos. Polis, (39), I-22. doi http://dx.doi.org//0.4067/S07/8$656820 \mid 4000300007$

Vaggione,J.M. (20I I). Introducción. En J. M. Morán Faúndes, M.C.SgróRuata, y J.M.Vaggione (eds.), Sexualidades, desigualdades y derechos. Reflexiones en torno a los derechos sexuales y reproductivos (pp. 13-55). Córdoba: Ciencia, Derecho y Sociedad-Universidad Nacional de Córdoba. Verón, E. (1987). La palabra adversativa. Observaciones sobre la enunciación política. En AA. VV., El discurso político. Lenguajes y acontecimientos (PP. I I-26). Buenos Aires: Hachette.

Verón, E. (1998). La semiosis social. Fragmentos de una teoría de la discursividad. Barcelona: Gedisa.

Verón, E. (2004). Fragmentos de un tejido. Buenos Aires: Gedisa. Verón, E. (20I3). La semiosis social 2. Ideas, momentos, interpretaciones. Buenos Aires: Paidós.

Zucchini, G. (1998). Oposición. En N. Bobbio, N., Matteucci, y G. Pasquini (eds.), Dicionário de política I (pp.846-85I). Brasilia: UNB. 